\title{
VISUALISASI 3D KOS MOSEIM SEBAGAI MEDIA PEMBELAJARAN MENGGUNAKAN TEKNIK AEC EXTENDED 3DS MAX
}

\author{
Benyamin Jago Belalawe
}

\author{
Program Studi Teknik Informatika, STIKOM Uyelindo Kupang \\ Jln. Perintis Kemerdekaan I - Kayu Putih - Kupang - NTT - Indonesia \\ Email : qq_gerald@yahoo.com
}

\begin{abstract}
Making learning media can create an effective, interesting, interactive and fun learning process. The usefulness of using diverse learning tools will be able to create learning variations. Current technological developments, especially in fields such as 3D. Learning media, especially 3D-based learning, can help users learn 3D. AEC (Architectural, Engineer, Construction) Extended is an extension of 3D features to make it easier for users to create 3D designs. The results of this study will be able to help facilitate users in creating 3D objects.
\end{abstract}

Keywords: 3D Visualization, Learning Media, AEC Extended 3DS Max Technique.

\section{PENDAHULUAN}

\subsection{Latar Belakang}

Teknologi merupakan sebuah alat yang digunakan penggunanya untuk mempermudah memenuhi kebutuhan, salah satu teknologi yang berkembang saat ini adalah teknologi citra tiga dimensi (3D) yang banyak digunakan untuk industri hiburan dan industri-industri besar terutama industri perfilman. Informasi yang dilengkapi dengan visualisasi dan animasi akan lebih mudah dipahami oleh semua pihak.

Pembuatan media pembelajarandapat menciptakan proses pembelajaran yang efektif, menarik, interaktif dan menyenangkan. Kegunaan lain dari penggunaan alat bantu pembelajaran yang beragam akan dapat menciptakan variasi belajar sehingga tidak menimbulkan kebosanan. Salah satu komponen penting dalam pembelajaran adalah media pembelajaran. Kedudukanmedia dalam pembelajaran sangat penting bahkan sejajar dengan metode pembelajaran, karena metode yang digunakan dalam proses pembelajaran biasanya akan menuntut media apa yang dapat diintegrasikan dan diadaptasikan dengan kondisi yang dihadapi. Zainal Arifin dan Adhi Setiyawan (2012: 126)[3]

Perkembangan dibidang animasi juga telah banyak membantu dalam visualisasi sehingga menjadi lebih kompleks dan canggih, alasannya karena selain memiliki sudut pandang lebih luas dari obyek dua dimensi (2D) yang hanya mempunyai satu sudut pandang saja obyek tiga dimensi (3D) juga dinilai lebih interaktif dan imajinatif karena obyek obyek akan sesuai dengan aslinya. Dengan multimedia akan dapat dibuat media pembelajaran yang lebih menarik dan interaktif. Penggunaan multimedia mampu membuat suatu terobosan baru dalam menciptakan dinamika kemasan data dan informasi dengan cara yang berbeda bukan dengan teks statis tetapi dengan animasi teks, gambar, suara, video serta 3 dimensi. Berdasarkan uraian tersebut maka dibuatlah media pembelajaran dengan tujuan pembelajaran khusus dibidang 3D.Media pembelajaran berbasis 3Dimensi yang dapat membantu masyarakat dalam mempelajari 3D dengan menampilkan objek - objek 3 dimensiyang lebih mudah dipahami dengan langkah-langkan pembuatan objek 3D.

\subsection{Rumusan Masalah}

Berdasarkan permasalahan tersebut maka dapat disimpulkan rumusan permasalahan sebagai berikut:

a. Bagaimana membuat sebuah visualisasi tiga dimensi sebagai media Pembelajaran.

b. Bagaimana cara belajar 3D menggunakan Teknik AEC Extetded 3DS Max. 


\subsection{Batasan Masalah}

Agar pembahasan tidak keluar dari topik, maka penulis membatasi permasalahan penelitian yaitu:

a. Media Pembelajaran yang didesain dengan studi kasus pada Kos Moseim.

b. Pemodelan 3D menggunakan objekobjek 3DMAx 2013.

c. Menggunakan Teknik AEC Extended.

\subsection{Tujuan dan Manfaat Penelitian}

Tujuan dari penelitian ini adalah membuat media pembelajaran visualisasi Kos Mosim dalam bentuk 3D dengan menggunakan Teknik AEC Extended.

\section{TINJAUAN PUSTAKA}

Agustina (2015), Pengembangan media pembelajaran teknik animasi 2 dimensi berbasis Adobe Flash untuk siswa kelas XImultimedia di SMK Muhamadiah Prambanan. Tujuannya adalah menghasilkan media pembelajaran Teknik Animasi 2 Dimensi dan mengetahui kelayakan media pembelajaran Teknik untuk mengetahui hasil belajar siswa setelah menggunakan media pembelajaran Teknik Animasi 2 Dimensi.[4]

Maulana dan Kusuma. (2014) Aplikasi Augmented RealitySebagai Media Pembelajaran Tata Surya, Penelitian ini bertujuan untuk membuat aplikasi media pembelajaran tentang tata surya. Saat ini pembelajaran tata surya hanya bisa dipelajari dari buku, video, internet ataupun datang langsung ke tempat yang mempelajari tentang tata surya seperti Planetarium. Hasil Penelitian ini memanfaatkan teknologi Augmented Reality (AR). AR sebagai penggabungan benda-benda nyata dan maya di lingkungan nyata, berjalan secara interaktif dalam waktu nyata dan terdapat integrasi antar benda dalam tiga dimensi (3D).[1]

Akip Suhendar Aditya Fernando.(2016) Aplikasi Virtual tour Berbasis MultimediaInteraktif Menggunakan Autodesk 3Ds MaxDengan virtual tour kita mampu menjelajahi suatu tempatuntuk mendapatkan informasi dan gambaran mengenai tempat tersebut hanya dengan menggunakan komputerdekstop, kios informasi atau media elektronik lainnya, tanpa harus susah payah untuk pergi ke tempat yangsebenarnya. Aplikasi virtualtour yang dikembangkan menggunakan first person controller diharapkan dapat memberikan informasi mengenailokasi ruangan dan fasilitas yang terdapat pada Universitas Serang Raya (UNSERA) serta memberikan gambaranyang lebih jelas mengenai tempat tersebut, tanpa harus berjalan menyusuri setiap lantai yang terdapat pada gedung. [2]

Hotmian Sitohang dan Muliawardi Astrianingsih. (2016) Aplikasi Simulasi 3 Dimensi Bangun Ruang Untuk SekolahDasar (SD) Berbasis Android.sebagai simulasi pembelajaran bangun ruang $3 \mathrm{D}$ yang bisadiimplementasikan dalam pembelajaran matematika sehingga muncul ketertarikan siswadan membantu siswa dalam belajar seharihari. aplikasi ini juga dilengkapidengan soal dan cara mengerjakannya.Hasil dari penlitian ini adalah aplikasi simulasi3Dbangun ruang berbasis android sebagai sarana pembelajaran bagi siswa SD yang berisitentang macammacam bangun ruang, materi, rumus, serta contoh soaldan caramenyelesaikan soal yang dapat membantu para siswa agar mudah dalam mempelajari bangunruang.[5]

Supriyadi. (2018) Media Pembelajaran Proses Rendering Objek 3D Berbasis Multimedia, Aplikasi disiapkan oleh prosedur yang mencakup mengidentifikasi masalah yang diperoleh, analisis kebutuhan,merancang konsep, merancang konten, merancang dokumen dan diagram navigasi, merancang skrip, merancanggrafik, sistem penghasil, sistem pengujian dengan kotak hitam dan uji alfa. Hasil dari penelitian ini adalah aplikasi multimedia sebagai media pembelajaran animasi 3D pada rendering objekmateri untuk mahasiswa Program Studi Siaran di AKOM BSI Jakarta yang berdasarkan hasil pengujian itu bisadisimpulkan bahwa aplikasi pembelajaran ini dapat membantu proses pembelajaran pada siswa untuk memahami materi dan dapat digunakan sebagai alat dosen untuk mendukung pembelajaran animasi 3D. [6] 


\section{METODE PENELITIAN}

\subsection{Studi Kepustakaan}

Dilakukan dengan mencari literatur pendukung penelitian yang mampumemberikan informasi yang memadai dalam menyelesaikan penelitian ini sertan membantu mempertegas teori-teori yang ada. Proses pengumpulan data dilakukandengan menggunakan metode studi pustaka yaitu dengan cara membaca sumbersumber yang terkait baik dari buku, jurnal, skripsi maupun internet

\subsection{Metode Observasi}

Observasi merupakan salah satu teknik pengumpulan data yang cukup efektifterhadap objek penelitian. Observasi dilakukan dengan cara mengadakanpengamatan langsung terhadap Kos Moseim untuk keakuratan data yang dibutuhkan

\subsection{Wawancara}

Melakukan tanya jawab langsung dengan pemilik Kos Moseim untukmengumpulkan data yang diperlukan secara face to face antara peneliti danpemilik Kos untuk memperoleh data yang dapat menjelaskan ataupun menjawabsuatu permasalahan penelitian.

\subsection{Prosedur Pengembangan Media Pembelajaran \\ Prosedur pengembangan program} menjelaskan secara rinci proses pembuatan media pembelajaran 3D. Proses produksi terdiri dari tiga tahapan, yaitu pra produksi, produksi, dan pasca produksi seperti tertera pada bagan berikut

1. Tahap pra produksi, meliputi kegiatan persiapan alat produksi, yaitu seperangkat komputer dan software-software pendukung dalam hal ini software yang paling utama adalah 3DsMax 2013 dan Camtasia Studio. Selain itu software yang perlu disiapkan adalah pinnacle 2012 yang berfungsi sebagai software pengolah video Pembuatan media pembelajaran.

2. Tahap produksi, meliputi membuat media pembelajaran yang telah direncanakan sebagai media pembelajaran kedalam bentuk grafis, animasi, teks, suara. Dari pembuatan desain grafis/animasi, maka akan diperoleh wujud nyata dari kerangka perancangan yang telah buat.
3. Tahap pasca produksi, meliputi kegiatan mengedit dan merender video, apakah ada kekurangan dalam video pembelajaran 3D yang telah dibuat.

\subsection{Perancangan Model Media Pembelajaran}

Dalam pembuatan media pembelajaran 3D dibutuhkan beberapa perancangan awal. Pada penelitian ini menggunakan Teknik AEC(Architectural, Engineeting, Construction)Extended sebagai salah satu perluasan dari fitur-fitur yang di ciptakan, untuk memudahkan para pengguna untuk membuat rancangan yang di buat sesuai konsep.

1. Perancangan Denah Kost Moseim

Pada perancangan denah model pembelajaran ini menggunakan skala 1:100, dengan ukuran 1 $\mathrm{cm}$ sama dengan $1 \mathrm{~m}$.Ukuran kamar $300 \mathrm{~cm} \mathrm{x}$ $400 \mathrm{~cm}$ dengan panjang bangunan secara keselurahan $1200 \mathrm{~cm}$ dan lebar $300 \mathrm{~cm}$. Setiap kamar masing-masing memiliki wc dan kamar mandi tersendiri.

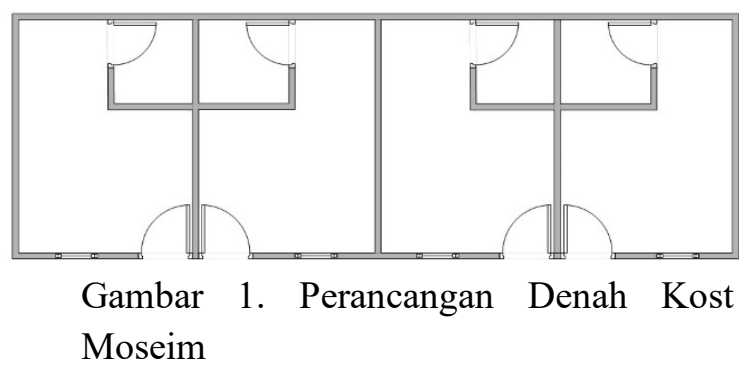

2. Perancangan Tampak Depan Kost Moseim Perancangan tampak depan model pembelajaran disesuaikan dengan ukuran tinggi bangunan yakni $350 \mathrm{~cm}$ dari tembok bawah sampai batas atas tembok, dengan ketinggian atap $150 \mathrm{~cm}$. Pada tampak depan juga disertakan dengan pintu dan jendela dengan ukuran lebar pintu $80 \mathrm{~cm}$ dan tinggi pintu 210 $\mathrm{cm}$, ukuran jendela dengan tinggi $150 \mathrm{~cm}$ dan lebar $60 \mathrm{~cm}$.

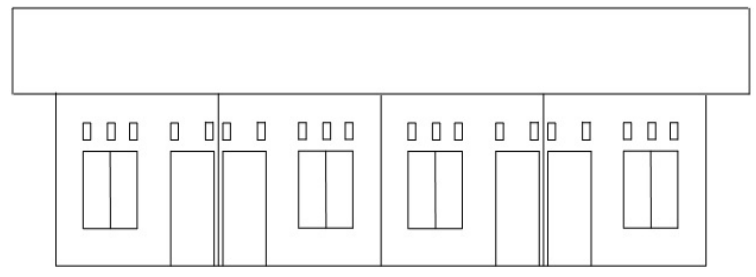

Gambar 2. Perancangan Tampak Depan 
3. Perancanagan Tampak samping Perancangan tanpak samping Kost Moseim mengacu pada lebar bangunan $400 \mathrm{~cm}$ dan ditambahkan teras $150 \mathrm{~cm}$.

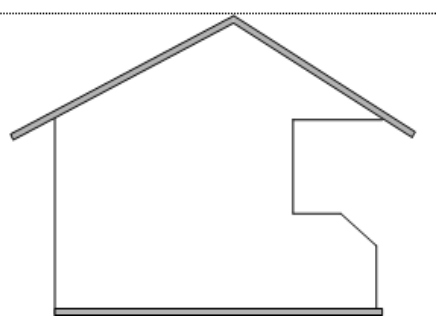

Gambar 3. Perancangan Tampak Samping

4. Tampak belakang Kost Moseim

Perancangan belakang Kost Moseim mengacu pada ukuran dengan bangunan dan ditambahkan tirisan air sebesar $50 \mathrm{~cm}$. Pada model bangunan asli dari pada kost Mosein tidak memiliki pintu pada bagian belakangnya.

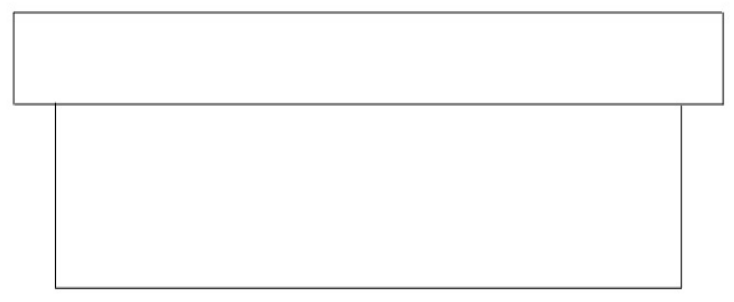

Gambar 4. Perancangan Tampak Belakang

\section{HASIL DAN PEMBAHASAN}

Bagian akhir dari pada media pembelajaran ini adalah dengan menambahkan pembatas antara kamar, diaman dapat memjaga privasi dari penghuninya dan menambahkan pohon sebagai perindang menggunakan material Folliage untuk material pohonya.

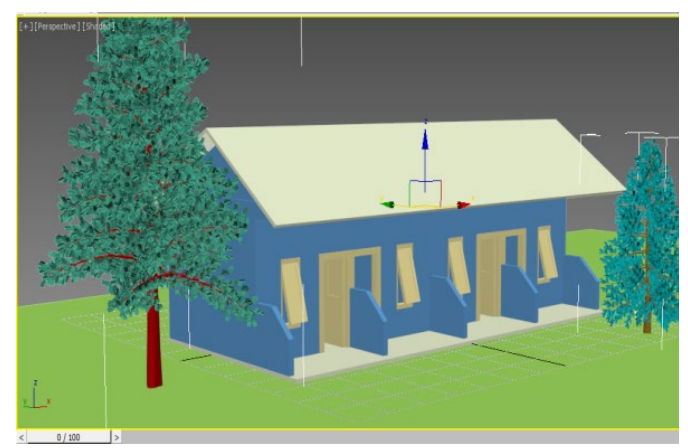

Gambar 5. Hasil Visualisasi Kos

Moseim

\section{KESIMPULAN}

\subsection{Kesimpulan}

Dari hasil penelitian yang dilakukan dapat disimpulkan bahwa:

a. Media pembelajaran 3D ini mudah dipahami dan layak untuk digunakan sebagai media pembelajaran bagi masisa maupun masyarakat umum dalam mempelajari 3 dimensi.

b. Media pembelajaran ini menggunakan Bahasa Indonesia sehingga dalam belajar mudah untuk dipahami.

\subsection{Saran}

Saran yang dapat berikan dalam penelitian ini adalah:

a. Dalam belajar 3D harus mengguankan computer atau laptop yang mampu mendukung aplikasi 3D.

b. Untuk peneliti lanjutan dapat membuat media lanjutan denan menambahkan materi Texturing, Animation dan Rendering

\section{DAFTAR PUSTAKA}

[1] Angga Maulana dan Wahyu Kusuma, 2014,Aplikasi Augmented RealitySebagai Media Pembelajaran Tata Surya, Prosiding Seminar Ilmiah Nasional Komputer dan Sistem Intelijen (KOMMIT 2014) Universitas Gunadarma Depok - 14-15 Oktober 2014 , Vol. 8 Oktober 2014, ISSN : 2302-3740

[2] Akip Suhendar, Aditya Fernando, 2016. Aplikasi Virtual tour Berbasis Multimedia Interaktif MenggunakanAutodesk 3Ds Max Program Studi Teknik Informatika Fakultas Teknologi Informasi - Universitas Serang Raya Jurnal ProTekInfo Vol. 3 No. 1 September 2016 ISSN: 2406-7741

[4] Candra Agustina. (2015) Pengembangan Media Pembelajaran Teknik Animasi 2 Dimensi Berbasis Adobe Flash Untuk Siswa Kelas XI Multimedia di SMK Muhammadiyah Prambanan, Skripsi, Program Studi Pendidikan Teknik Informatika Fakultas Teknik Universitas Negeri Yogyakarta

[5] Hotmian Sitohang dan Muliawardi Strianingsih, 2016.Aplikasi Simulasi 3 Dimensi Bangun Ruang Untuk Sekolah 
HOAQ: JURNAL TEKNOLOGI INFORMASI

Volume 10 Nomor 1 - Mei 2018, Hal 1-5

Dasar (SD) Berbasis AndroidSTMIK

Palangkaraya.

Jurnal Teknologi Technoscientia ISSN:

1979-8415 Vol. 8 No. 2 Februari 2016

[6] Supriyadi, 2018. Media Pembelajaran

Proses Rendering Objek 3D Berbasis

Multimedia. JurnalTeknik Komputer.

Volume 2 No. 2 Agustus 2018 P-ISSN

2442-2436, E-ISSN: 2550-0120 